\title{
Erratum to: Late fixation of vertically unstable type-C pelvic fractures: difficulties and surgical solutions
}

\author{
Osama Farouk • Wael El-Adly • Yaser E. Khalifa
}

Published online: 19 August 2014

(C) EFORT 2014

Erratum to: European Orthopaedics and Traumatology DOI 10.1007/s12570-014-0266-y

Unfortunately, one of the co-author names has been misspelled. The third name should be changed from Yaser E. Khalefa to Yaser E. Khalifa.

The online version of the original article can be found at http://dx.doi.org/ 10.1007/s12570-014-0266-y.

O. Farouk $\cdot$ W. El-Adly $(\bowtie) \cdot$ Y. E. Khalifa

Orthopaedic Department, Assiut University, Assiut 71111, Egypt

e-mail: eladlyw@yahoo.com 